\title{
DAMPAK PENGETAHUAN SEKSUAL TERHADAP PERILAKU SEKS REMAJA DI KECAMATAN MANGGALA KOTA MAKASSAR
}

\author{
Dian Ayu Lestari ${ }^{1}$, A. Octamaya Tenri Awaru ${ }^{2}$ \\ ${ }^{1,2}$ Program Studi Pendidikan Sosiologi, Fakultas Ilmu Sosial, Universitas Negeri Makassar \\ dian_aylez@yahoo.com ${ }^{1}$, a.octamaya@unm.ac.id ${ }^{2}$
}

\begin{abstract}
ABSTRAK
Tujuan penelitian ini untuk mengetahui: 1) bagaiamana bentuk pengetahuan seksual anak remaja; 2) bagaimana dampak pengetahuan seksual terhadap perilaku seksual remaja. Jenis penelitian ini kualitatif deskriptif, informan dipilih melalui teknik purposive sampling dengan kriteria yaitu anak remaja Kecamatan Manggala Kota Makassar yang pernah mengikuti sosialisasi seks bebas, berusia 15-18 tahun. Teknik pengumpulan data yang digunakan yaitu wawancara, dan observasi. Data yang diperoleh dianalisis dengan tahapan mereduksi data, menyajikan data dan penarikan kesimpulan. Teknik pengabsahan data menggunakan triangulasi sumber. Hasil penelitian menunjukkan bahwa: 1) Bentuk pengetahuan seksual anak renaja di Kecamatan Manggala Kota Makassar, yaitu a) meliputi aspek pengetahuan siklus biologis (organ reproduksi), b) pengetahuan aspek norma dan batasan perilaku seksual, c) pengetahuan tentang peran dan fungsi secara seksual, dan d) Pengetahuan aspek kesehatan organ reproduksi. 2) Dampak pengetahuan seksual anak terhadap perilaku seks remaja di Kecamatan Manggala Kota Makassar, yaitu a) dampak positif: membantu menghindari tindakan penyimpangan dan abnormalitas seks, membantu mengidentifikasi baligh pada diri remaja dan memberikan pemahaman peran dari jenis jender; b) dampak negative: munculnya rasa penasaran yang tidak sehat dan munculnya perilaku menyimpang seksual akibat sosialisasi tidak sempurna.
\end{abstract}

Kata kunci: Pengetahuan Seksual, Perilaku Seks Remaja

\begin{abstract}
The purpose of this study was to determine: 1) how the forms of adolescent sexual knowledge; 2) how the impact of sexual knowledge on adolescent sexual behavior. This type of research is qualitative descriptive, the informants were selected through a purposive sampling technique with criteria, namely teenagers from Manggala District, Makassar City who had participated in free sex socialization, aged 15-18 years. Data collection techniques used were interviews and observation. The data obtained were analyzed by the stages of reducing data, presenting data and drawing conclusions. The data validation technique uses source triangulation. The results showed that: 1) The forms of sexual knowledge of children in the district of Manggala Makassar, namely a) include aspects of biological cycle knowledge (reproductive organs), b) knowledge of norms and limits on sexual behavior, c) knowledge of sexual roles and functions, and d) Knowledge of health aspects of reproductive organs. 2) The impact of children's sexual knowledge on adolescent sexual behavior in the District of Manggala, Makassar City, namely a) positive impact: helps avoid acts of sexual deviations and abnormalities, helps identify teenage age in adolescents and provides an understanding of the role of gender; $b$ ) negative impact: the emergence of unhealthy curiosity and the appearance of sexual deviant behavior due to imperfect socialization.
\end{abstract}

Keywords: Sexual knowledge, teenager sex behavior

\section{PENDAHULUAN}

Pendidikan seks seharusnya menjadi sebuah bekal untuk anak yang memasuki masa remaja. Anak yang mendapatkan pendidikan seksual yang baik dengan sendirinya memiliki pengetahuan seksual yang tuntas. Dalam artian informasi seksual yang mereka peroleh dari media sosial, teman sebaya telah mendapatkan pendampingan dari orangtuanya. Anak- yang telah menadaptkan pendidikan seksual dari orangtuanya memilki rasa percaya diri yang baik serta memiliki pengahargaan pada diri yang tinggi. Sehingga mereka tidak mudah terbujuk untuk melakukan seks bebas. Anak remaja yang memilki 
pengetahuan seksual yang memadai akan memiliki cara untuk mengahadapi kekerasan, pelecehan atau kejahatan seksual yang akhir-akhir ini semakin marak, yang korbannya kebanyakan adalah anak remaja.

Anak memilki beragam rasa ingin tahu, salah satu yang ingindiketahuinya adalah masalah seks. Perkembangan gender dan seksualitas pada anak-anak dimulai dari hal yang paling mendasar, antara lain pada usia tiga tahun anak sudah dapat membedakan jenis kelamin dan perbedaan fisik yang menyertainya (Lestari, 2016). Seksualitas berkembang sejak masa anak-anak, remaja, sampai dewasa. Perkembangan ini meliputi perkembangan fisik dan psikis, perkembangan secara psikis berupa perkembangan psikoseksual yang terjadi pada masa anak-anak (Hildayani, Sugianto, Tarigan, \& Handayani, 2014).

Menutup informasi masalah seksual kepada anak justru kurang bijaksana bagi proses pendidikan seks anak dan keluarga karena masalah seksual tidak hanya selalu masalah hubungan intim, tetapi mencakup banyak elemen seperti pemahaman alat kelamin secara biologis, fisiologis dan fungsi hormonal, pemahaman gender dan seksualitas, pemahaman hasrat seksualitas, pemahaman komunikasi seksualitas, pemahaman sumber rangsangan seksualitas, pemahaman akil baligh, pemahaman seksualitas pada anak, remaja, dewasa dan usia lanjut, pemahaman hak pilih anak, pemahaman orientasi seksualitas, pemahaman unsur genetis seksualitas, pemahaman kejahatan seksualitas dan hukumnya, pemahaman kebijakan publik berkaitan dengan aspek seksualitas masyarakat. (Awaru, 2019)

Oleh karena itu anggapan orangtua yang masih menganggap bahwa pendidikan seks adalah hal yang berhubungan dengan hal intim, kotor dan bahkan tak pantas dibahas dan diberikan kepada anak harus diluruskan. Bahwasanya pendidikan seks yang syarat dengan etika dan moral telah dilakukan oleh orangtua terdahulu melalui berbagai cara. Pendidikan seks juga dapat membantu anak untuk lebih menghindari diri dari seks bebas, dan juga dengan pendidikan seks orangtua dapat memberikan gambaran pada anak bahwa seks adalah sesuatu ilmiah dan wajar terjadi pada semua orang, selain itu anak juga dapat diberitahu mengenai berbagai perilaku seksual yang beresiko sehingga mereka dapat menghidarinya.

Kurangnya pendidikan seks orangtua kepada anak membuat rasa ingin tahu anak memuncak dan memilih untuk mencari informasi mengenai seks melalui media internet, dimana informasi yang akan mereka dapat tidak tersaring dan bahkan belum pantas untuk mereka cerna, seperti halnya gambar porno, cerita dewasa dan bahkan video yang menampilkan hubungan suami istri. (Awaru, Idris, \& Agustang, 2018) Kurangnya pendidikan seks dan kontrol diri akan membawa anak kearah pergaulan seks bebas, seperti yang kita ketahui seks bebas sangat berdampak buruk bagi kehidupan seseorang.

Prilaku seksual pada remaja sangat bergantung pada pengetahuan seksual yang dimilki oleh anak. Perilaku seksual adalah perilaku yang berhubungan dengan fungsifungsi reproduktif atau yang merangsang sensasi dalam reseptor-reseptor yang terletak pada atau yang di sekitar organ-organ reproduktif atau daerah-daerah erogen. Hasil penelitian menunjukkan bahwa rendahnya pengetahuan tentang seks dan kontrol dari orangtua dapat membuat remaja berperilaku seksual berisiko. Pengetahuan seks yang kurang menjadi salah satu penyebab perilaku seks bebas yang saat ini cukup parah terjadi. Perilaku tersebut dapat dipicu melalui tayangan-tayangan yang berada di internet dan media sosial lainnya.

Di Kota Makassar angka perilaku seks bebas menduduki peringkat tertinggi dari seluruh Kabupaten yang ada di Sulawesi Selatan (Azis, 2011). Salah satu Kecamatan yang tingkat perilaku seks bebasnya tinggi terkhsusu pada usia remaja adalah di Kecamatan 
Manggala. Melihat keterhubungan antara pengetahuan seks dengan prilaku seksual maka saya tertarik untuk melakukan penelitian yang bertujuan untuk mengetahui bagaiamana bentuk pengetahuan seksual anak remaja dan bagaimana dampak pengetahuan seksual terhadap perilaku seksual remaja.

\section{METODE PENELITIAN}

Dalam penelitian ini, penulis akan menggunakan metode penelitian kualitatif deskriptif. Pendekatan deskriptif bertujuan untuk menggambarkan dan menginterpretasi objek sesuai dengan apa adanya (Sukmadinata, 2005). Lokasi Penelitian ini di Kecamatan Manggala Kota Makassar. Informan penelitian sebanyak 15 orang yang dipilih secara purposive sampling. Kriteria informan penelitian adalah remaja yang berdomisili di Kecamatan Manggala, berusia 16-19 tahun serta perna mengikuti sosialisasi seks bebas. Teknik pengumpulan data yang digunakan yaitu wawancara dan observasi. Data yang diperoleh dianalisis dengan dengan tiga tahap yaitu tahapan reduksi data, display data dan penarikan kesimpulan. (Huberman \& Miles, 2002) Teknik pengabsahan data yaitu triangulasi sumber dalam hal ini setelah melakukan wawancra dengan remaja maka dilakukan wawancara dengan orangtua untuk mengaetahui ke validan data yang diberikan oleh anak remaja..

\section{HASIL PENELITIAN DAN PEMBAHASAN}

Kecamatan Manggala merupakan salah satu dari 14 kecamatan di kota Makassar dengan luas wilayah 24,14kilometer atau sekitar 13,17\% dari luas wilayah Kota Makassar yang terbagi kedalam 7 wilayah Kelurahan. Kecamatan Manggala dibatasi oleh kecamatan Tamalanrea di sebelah utara, Kbupaten Gowa di sebelah selatan, Kecamatan Panakkukang di sebelah Barat dan Kabupaten Maros di sebelah Timur. Sejak tahun 2017 Kecamatn ini memiliki 7 kelurahan dengan luas $24,14 \mathrm{~km} 2$.

\section{Bentuk pengetahuan seksual anak di Kecamatan Manggala Kota Makassar}

Pengetahuan seks merupakan sebuah hal yang agak menuai penafsiran dan konotasi negative, namun hal ini penting sebab memiliki korelasi dengan kehidupan baik secara individu dan keluarga kelak. Untuk itu diharapkan orang tua mampu memberikan pengarahan dan pemahaman bagi anak itu sendiri agar tidak terlalu kaku memandang hal tersebut. Sebagai keluarga tentunya memegang peranan penting dalam memberikan pemahaman kepada anak mengenai pengetahuan seks. Berdasarkan hasil penelitian bentuk pengetahuan seks anak remaja di Kecamatan Manggala adalah:

Pertama, yaitu Pengetahuan aspek siklus biologis (organ reproduksi), hal ini berkaitan dengan bagaimana individu paham akan konsis biologi yang dialaminya misalnya ketika mensetruasi, atau mimpi basah, hal ini tentunya membantu individu mengenali dirinya, memberikan pengetahuan seputar hal tersebut. Bentuk pengetahuan seksual yang pertama ini adalah pengatahuan paling dasar yang perlu diketahui oleh individu agar mereka tidak kaget atau takut ketika berada pada fase baligh. Ketika anak mengalami mimpi basah bagi laki-laki dan mengalami menstruasi bagi anak perempuan, mereka harusnya sudah siap atau paham akan hal seperti itu atau fase seperti itu adalah hal yang pasti atau mutlak akan dilalui oleh setiap anak di kehidupanya.

Bilamana mereka tidak pernah mendapatkan pengetahuan tentang hal tersebut maka anak akan merasa kaget dengan fase yang akan mereka lalui, oleh karena itu pengetahuan seksual dalam aspek siklus biologis sangat perlu diberikan dan didapatkan oleh anak sebelum memlaui fase tersebut. Anak yang mendapatkan pengetahuan seksual 
akan melewati fase tersebut tanpa perlu merasa kaget karena mereka telah memahami apa yang terjadi adalah hal mutlak yang pasti akan mereka lalui. Hal ini seperti yang dijelaskan oleh Rasyid bahwa pendidikan seks juga memiliki muatan yang menjadi topic pembahasan yang jelas, lebih lanjut dijelaskan cakupan yang menjadi acuan materi pendidikan seks untuk membentuk pengetahuan seks pada anak salah satunya adalah pada point 2 yaitu identifikasi baligh.

Bentuk pengetahuan kedua yaitu, pengetahuan aspek norma dan batasan perilaku seksual. Pada aspek inilah seharusnya menjadi sebuah hal yang teramat penting sebab dengan memahami aturan dan norma tersebut seorang individu akan terhindar dari perilaku menyimpang seksual, seperti seks bebas, tertural penyakit seksual serta kelainan seksual (homo dan lesbi). Hal tersebut sesuai tentunya membantu individu dalam memilah tindakan yang mereka lakukan apakah tindakan tersbut sesuai dengan norma ataukan tidak sesuai norma.

Aspek norma dan batasan-batasan dalam berperilaku seksual tentunya menjadi pengethuan seksual yang amat sangat penting karena anak yang tidak mendapatkan pengetahuan akan batasan-batasan perilaku seksual anak akan sangat mudah terbawa dan terjerumus kedalam lingkungan yang menyimpang seperti halnya homoseksual dan lesbian. Apabila mereka mengetahui batasan batasan dan apek norma maka mereka akan menghindari akan norma seksual maka akan sangat mudah bagi seorang anak terjerumus ke arah pergaulan yang keluar dari batasan batasan tersebut.

Bilamana mereka melewati fase bertumbuh dewasa tanpa pengetahuan akan batasakn dan Lebih lanjut pengetahuan ini juga termasuk upaya pencegahan dini dari tindakan yang abnormalitas seks, seperti yang dijelaskan dalam Abu Ahmadi dan Nur bahwa pendidikan seks dalam menbetuk pengetahuan seks sebagai alternative dalam menaggulangi degradasi moral hatus menjadi perhatian".

Bentuk pengetahuan seksual yang ketiga yaitu pengetahuan tentang peran dan fungsi secara seksual. bentuk ini individu harus memahami bahwa secara seksual memiliki fungsi yang berbeda seperti perempuan tentunya memiliki peran dan fungsi bereda mereka lebih cenderung untuk mengandung dan melahirkan anak, sedangkan kalau laki-laki tidak. Hal seperti ini juga perlu dipahami agar individu tersebut paham dan mengetahui hal-hal yang perlu dihindari. Sebagai contoh banyak perempuan susah untuk mengandung kerena mengalami cedera waktu masih mudah seperti kerusakan pada rahim kerena pernah jatuh atau kecelakaan, atau karena sering mengkomsumsi minuman yang berbahaya seperti alcohol dan lain sebagainya.

Pada aspek ini pengetahuan berupaya mengarahkan pada perilaku sesuai dengan fungsi dan peran secara gender. Anak anak harus sadar akan peran dan fungsi gender mereka masing masing agara mereka tidak merasa terlahir dengan raga dan jiwa yang berbeda. Mereka merasa seharyusnya lahir sebagai perempuan tapi memliki tubuh laki-laki seperti sebaliknya dimana banyak laki-laki yang merasa harusnya terlahir sebagai perepuan namun memiliki raga seorang laki-laki.

Pikiran seperti itulah yang harusnya dihindarkan atau dihilangkan dari seorang anak. Mereka harus paham mengapa mereka bisa merasa berada ditubuh yang salah. Pemahaman terebut sangat penting bila kita melihat sejauh ini begitu banyaknya transgender yang terekspos oleh media yang membuat anak laki-laki yang jiwa feminimnya sangat besar dalam diri merasa terdukung akan hal itu dan juga sebaliknya, anak perepuan yang merasa jiwa kelaki-lakiannya sangat besar dalam dirinya. Oleh karena itu pengetahuan akan peran dan fungsi seksual sangat perlu dan penting untuk anak. 
2. Dampak pengetahuan seksual anak terhadap prilaku seksual remaja di Kecamatan Manggala Kota Makassar

Pengetahuan seksual yang dimiliki seseorang tentunya memiliki sebuah dampak yang ditimbul, jika ditelusuri lebih dalam maka hal tersebut memiliki berbagai dampak seperti dampak postif dan negative.

A. Dampak positif

1) Membantu anak menghindari tindakan penyimpangan dan abnormalitas seks.

Pengetahuan seks yang dimiliki seseorang akan membantunya menghindari penyimpangan. (Setiawan, 2019)Sebab seperti yang dijelaskan pada bagian sebelumnya jelas bahwa pengetahuan seksual yang dimilki individu akan menggiring dirinya mampu mengidentifikasi tindakan-tindakan dan perilaku yang mengarah serta menjerumuskan kearah negative lebih. Hal tersebut sesuai dengan hasil wawancara sebaagai berikut:

"Seseorang yang sudah memahami aspek norma dan pengetahuan seksual lainnya idealnya kak menghindari dari perilaku-perilaku yang menyimpang kayak homo seksual dan juga lesbian. Karna ditau mi bahwa hal seperti itu adalah sebuah gejala abnormal". (Wawancara, AS, 19 Tahun)

Salah satu dampak positif dari pengetahuan seksual pada anak yaitu mengarahkan anak untuk bertindak sesuai norma dan menjauhi bentuk penyimpangan khususnya penyimpangan seksual atau abnormalitas seks seperti LGBT (Ermayani, 2017), (Budiarty, Cangara, \& RAF, 2011). Dengan bekal pengetahuan seks yang diperolehnya mereka menjadi tahu penciri dari orang yang mengalami gejala-gejala kelainan seksual.

2) Membantu memahami kesehatan, dan identifikasi baligh

Salah satu dampak positif dari pengetahuan seksual terhadap perilaku seksual remaja adalah membantu memahami kesehatan dan indentifikasi baligh. Sebagaimana hasil wawancara dengan salah satu informan berikut ini:

"Pengetahuan seksual yag didapat baik dari orang tua, ataupun artikel tentunya sangat membantu, apa lagi saat pertama kali dating bulan, ada ketakutan akan tetapi saat dikomuniksaikan dengan orangtua mereka mengatakan hal itu hal yang baiasa terjadi pada anak perempuan. Orangtua menyatakan bahwa saya itu tandanya saya telah dewasa. Selain itu orangtua saya juga menyampaikan bebeapa tanda saat haid akan dating misalnya merasa nyeri di bagian perut atau biasanya ditandai dengan sakit kepala dan lain-lain. Orangtua menyampaikan agar saya mengenali diri say suapay tau apa yang harus saya lakukan saat haid datang”. (Wawancara, DA, 17 tahun)

"Dengan pengetahuan yang kita milikikita tentunya mmapu memahami kondisi-kondisi tertentu eperti ketika kita mimpi basah, bahwa jalau kita seperti ini kita sudah beraanjak dewasa, dan tentunya kita juga paham bahwa harus ki membersihkan diri dan lain sebagainya". (Wawancara, AA, 17 Tahun)

Perkembangan seorang individu tentunya memiliki tahap-tahap, salah satunya adalah fase remaja menuju dewasa atau dikenal dengan istilah baligh. Kondisini adalah fase alamiah yang lalui seorang individu. Biasnaya pada fase ini perlu pengathuan seksual yang memedai dalam mengidentifikasi tandanya, misalnya bagi wanita yang sudah baligh tentunya akan mengalami menstruasi sedangkan bagi laku-laki mengalami mimpi basah. Fenomena seksual ini tentunya memerlukan sebuah pemahaman dan pengetahuan individu agar dia tidak kaget mengalami hal tersebut.(Madani, 2003) 
3) Memberikan pemahaman peran dari jenis gender dan bekal awal dalam berkeluarga

Pengetahuan yang dimiliki seorang anak perihal seksualitas tentunya menjadi sebuah bekal nantinya ketika berkeluarga serta Mengurangi ketakutan dan kecemasan sehubungan dengan perkembangan dan penyesuaian seksual (peran, tuntutan dan tanggung jawab). Sebagaimana hasil wawancara berikut ini:

"Kalau peran kak pasti diajarkan jki sama orangtua ta semua, bukan Cuma soal laki-laki harus cari uang tapi juga tentang kita lahir sebagai laki-laki jadi harus mati sebagai laki-laki, karena banyak tetanggaku itu bencong kak, dia selalu bilang saya ini perem[puan tapi lahir dengan tubuh laki-laki itumi sifatnya sama kelakuannya kayak perempuan padahal laki-laki kak, itumi ditekankan ka sama orangtua ku kalau tidak ada itu istilah lahir dengan tubuh yang salah, karena masing masing harus tau peran dan fungsinya masing-masing". (Wawancara, FN, 16 Tahun)

Pengetahuan seksual mampu memberikan pemahaman awal bagi individu tentang fungsi dan perannya secara gender sebagai bekal nanti ketika mereka sudah berkeluarga.

\section{B. Dampak Negative}

Terlepas dari segala bentuk dampak positif di atas, tentunya kita juga harus memahami bahwa pengetahuan seksual pada anak juga kadang memicu terjadinya penyimpangan, ini disebabkan oleh adanya rasa penesaran, rasa ingintahu yang lebih pada diri individu itu sendiri, adapun beberapa dampak negative dari oengetahuan seksual pada anak yaitu sebagai berikut:

1) Munculnya rasa ingin tahu yang tidak sehat

Pengetahuan seks hakikatnya memberikan pemamahaman bahwa bagi indiviud tentang seks itu sendiri, namun manusia tentunya memilki hastrat dan nafsu sendiri, hal ini tentunya mendorong individu melakukan sesuatu yang melampaui batas penegtahuannya, disinilah muncul perilaku seks bebas akibat dari pengetahuan seks yang tidak sempurna itu, banyak hari ini remaja yang gagal memamhami dan menangkap pesan dari pendidikan seks itu sendiri dan akhirnya terjerumus dalam tindakan maksiat. Sebagaimana hasil wawancara di bawah ini:

"pengetahuan seks yang dipahami kadang kak, membuat $k$ ita menjadi penasaran untuk membuktikan hal tersebut, disinilah kak kadang kita terjerumus ki kedalam seks pranikah, hingga pada seks bebas kak."

(Wawancara, AS, 18 tahun)

Pengetahuan seks yang diapat oleh anak cenderung berdampak negative karena menimbulkan rasa penasaran. Rasa penasaran ini kemudian membutuhkan penyaluran dan mereka biasanya mencari melalui media sosial, karena lingkungan keluarga tidak mendukung. Inilah salah satu pentingnya pendidikan seksual, keran pengetahuan yang didapat diluar orangtua akhirnya bisa diklarifiaksi oleh orangtua. Jika pengethauan seks ini tidak mendapatkan control dan pendampingan maka bisa saja menjerumuskan pada penyimpangan seperti seks bebas, seks diluar nikah, bermaksiat di tempat prostitusi dan lain sebagainya. Hal ini timbul karena individu merasa penasaaran dan tidak mampu mengontrol perilakunya sendiri.

2) Munculnya perilaku menyimpang seksual akibat sosialisasi tidak sempurna

Masih berkaitan dengan point sebelumnya, penyimpangan seksual ini sendri menjalaskan tentang perilaku seks yang tidak sesuai aturan seperti homo seksual, dan 
lesbian. Perilaku ini adalah dampak negative dari penegtahuan seksual anak yang tidak matang. Atau dalam sosiologi disebut sebagai sosialisasi tidak sempurna.

Hal ini timbul akibat pengetahuan seksual anak yang tidak secara lengkap artinya si anak tidak mampu memahami seutuhnya perihal seks tersebut, sehingga di mencari lewat artikal, internet dan lainnya. Terkadang ada konten materi, artikel dan juag bahan referensi lainnya yang justru tidak sesuai, sehingga si anak yang berada pada fase mencari tahu, akhirnya gagal paham dan memahami hal yang menyimpang. Hal tersebut sesuai dengan wawancara sebagai berikut:

"Perilaku seks menyimpang ini timbul karena ketik pahaman anak-anak kak, biasnaya mungkin mereka berteman dan mendapatkan pengetahuan yang salah, seperti sering pergi kesalon tapi disalon tersebut pegawainya adalah waria, nha lama kelamaan naka ini yang sering kesalon tersebut akan mulai bersosialiasi sehingga di terjerumus menjadi waria juga dan justru menyukai sesama jenis". (Wawancara, AKM, 18 Tahun)

Individu yang tidak memiliki pengetahuan dengan baik, kemungkin dia gagal paham tentang sesuatu yang dipelajarinya seperti konten materi, artikel dan juag bahan referensi lainnya yang justru tidak sesuai, sehingga si anak yang berada pada fase mencari tahu, akhirnya gagal paham dan memahami hal yang menyimpang. Seperti misalnya anak yang membaca artikel yang menjelaskan bahwa homoseksual merupakan sebuah trend atau sudah menjadi gaya hidup anak modern, dimana anak tersebut tidak paham akan hal hal yang menjadi faktor pendorong seorang menjadi homoseksual maka anak tersebut mulai mencoba membuka diri dan merasa nyaman dengan gaya hidup sebagai homoseksual akhirnya anak tersebut terjebak dalam situasi yang awalnya hanya karena coba-coba dan akhirnya terjebak rasa nyaman.

\section{PENUTUP}

Bentuk pengetahuan seksual anak di Kecamatan Manggala Kota Makassar, yaitu meliputi aspek pengetahuan siklus biologis (organ reproduksi), kedua adalah pengetahuan aspek norma dan batasan perilaku seksual, ketiga yaitu tentang peran dan fungsi secara seksual, dan yang keempat tentang Pengetahuan aspek kesehatan organ reproduksi. Dampak pengetahuan seksual anak terhadap perilaku anak di Kecamatan Manggala Kota Makassar, yaitu dampak positif berupa Membantu menghindari tindakan penyimpangan dan abnormalitas seks, kedua Membantu mengidentifikasi baligh pada diri individu sedangkan yang ketiga adalah Memberikan pemahaman peran dari jenis jender dan bekal awal dalam berkeluarga nantinya. Sementara dampak negatifnya yaitu Munculnya rasa ingin tahu yang tidak sehat dan munculnya perilaku menyimpang seksual akibat sosialisasi tidak sempurna

\section{DAFTAR PUSTAKA}

Awaru, A. O. T. (2019). Rekonstruksi Pendidikan Seksual Pada Orangtua di Kota Makassar. Universitas Negeri Makassar.

Awaru, A. O. T., Idris, R., \& Agustang, A. (2018). Sexual Education at High School Sinjai East. 1st International Conference on Social Sciences (ICSS 2018). Atlantis Press.

Azis, A. (2011). Angka Prilaku Seks Bebas Masih Tinggi di Makassar. Koran Tempo. Retrieved from https://koran.tempo.co/read/makassar/196805/angka-perilaku-seksbebas-masih-tinggi-di-makassar?

Budiarty, A., Cangara, S., \& RAF, N. (2011). Gaya hidup lesbian (Studi kasus di kota 
Makassar).

Ermayani, T. (2017). LGBT dalam Perspektif Islam. HUMANIKA, 17(2), 147-168.

Hildayani, R., Sugianto, M., Tarigan, R., \& Handayani, E. (2014). Psikologi perkembangan anak.

Huberman, M., \& Miles, M. B. (2002). The qualitative researcher's companion. Sage.

Lestari, W. (2016). Parent Role In Sex Education In Teenagers. UNIVERSITAS MUHAMMADIYAH SURAKARTA.

Madani, Y. (2003). Pendidikan seks untuk anak dalam Islam: panduan bagi orang tua, guru, ulama, dan kalangan lainnya. Zahra Publishing House.

Setiawan, A. (2019). PENDIDIKAN SEKS PADA ANAK (Studi Perbandingan Pemikiran Abdullah NashihUlwan dan Yusuf Madani) Ade Setiawan. IAIN.

Sukmadinata, S. N. (2005). Metode Penelitia. Bandung: PT Remaja Rosdakarya. 